\title{
Desempenho de cultivares e novas linhagens de amendoim na região central do Tocantins
}

\author{
Submetido - 20 Jul. 2021 \\ Aprovado - 07 nov. 2021 \\ Publicado - 15 dez. 2021
}

http://dx.doi.org/10.52755/ sas.v2iedesp2.148

Sistemas de Produção - Embrapa, Palmas, TO. E-mail: valdinei.sofiatti@embrapa.br.

Valdinei Sofiatti (iD

Jair Heuert ${ }^{\text {iD }}$

Programa de Melhoramento do Amendoim - Embrapa, Santo Antônio de Goiás, GO. E-mail: jair.heuert@embrapa.br.

Maxuel Fellipe Nunes Xavier ${ }^{\text {iD }}$

Discente de Agronomia do IFMT Campus São Vicente - Centro de Referência de Campo Verde, Campo Verde, MT. E-mail: maxuelfellipe90@gmail.com.

Taís de Moraes Falleiro Suassuna (D) Programa de Melhoramento do Amendoim - Embrapa, Santo Antônio de Goiás, GO. E-mail: tais.suassuna@embrapa.br.

\section{RESUMO}

O estado do Tocantins é um importante produtor de grãos da região Norte do Brasil, que tem potencial para a produção de amendoim de elevada qualidade, visando atender à crescente demanda por este produto nos mercados interno e externo. Este trabalho teve o objetivo de avaliar seis linhagens de amendoim do tipo Runner alto oleico (1253 OL, 1952 OL, 2055 OL, 2101 OL, 2133 OL e 2136 OL) na área experimental da Embrapa, em Palmas-TO. As cultivares BRS 421 OL e BRS 423 OL foram utilizadas como testemunhas. Foi utilizado o delineamento em blocos casualizados com quatro repetições, sendo avaliadas seis linhagens na safra 2019/20 e quatro linhagens na safra 2020/21. O manejo das áreas seguiu as recomendações para produção comercial de amendoim, incluindo controle químico de plantas daninhas e doenças foliares. Os dados foram submetidos à análise estatística por meio de modelos mistos (REML/BLUP) utilizando o software Selegen. A significância dos efeitos de tratamentos foi testada por meio da análise de variância. Não houve diferença estatísticas entre os tratamentos (cultivares e linhagens), nos dois anos de avaliação. Porém, a média geral do experimento na safra 2019/20 (3.676,0 kg.ha-1) foi menor que a da safra 2020/21 (5.895,6 kg.ha-1). Em 2019/20, foi observado amarelecimento geral das plantas, embora não houvesse deficiência de nitrogênio ou outro fator associado ao manejo; amostras de sementes com deformações, manchas, rachaduras e avermelhamento da película também foram observados. Estes sintomas são muito semelhantes aos sintomas causados por mancha anelar, uma doença de etiologia virótica detectada em amendoim nos estados de São Paulo e Goiás. Com isso, é importante continuar a avaliação de novas linhagens, visando desenvolver cultivares mais produtivas $e$ adaptadas ao cultivo em Tocantins, como também elucidar a etiologia dos sintomas observados na área experimental na safra 2019/20.

Palavras-chave: Arachis hypogaea L., Programa de Melhoramento de Amendoim; Região Norte.

\section{Performance of cultivars and new peanut lines in the} Tocantins

\section{ABSTRACT}

Este é um trabalho de acesso aberto e distribuído sob os Termos da Creative Commons Attribution Attribution-NonCommercial-ShareAlike 4.0 International. 
The state of Tocantins is an important grain producer in the northern region of Brazil, which has the potential to produce high quality peanuts, aiming to meet the growing demand for this product in the domestic and foreign markets. This work aimed to evaluate six high oleic Runner type peanut lines (1253 OL, 1952 OL, 2055 OL, 2101 OL, 2133 OL and 2136 OL) in the experimental area of Embrapa, in Palmas-TO. The cultivars BRS 421 OL and BRS 423 OL were used as controls. A randomized block design with four replications was used, with six lines in the 2019/20 harvest and four lines in the 2020/21 harvest being evaluated. The management of the areas followed the recommendations for commercial peanut production, including chemical control of weeds and foliar diseases. Data were subjected to statistical analysis using mixed models (REML/BLUP) using the Selegen software. The significance of treatment effects was tested using analysis of variance. There was no statistical difference between treatments (cultivars and strains) in the two years of evaluation. However, the overall average of the experiment in the 2019/20 crop (3,676.0 kg. ha-1) was lower than that of the 2020/21 crop (5,895.6 kg.ha-1). In 2019/20, a general yellowing of the plants was observed, although there was no nitrogen deficiency or other factor associated with the management; seed samples with deformations, spots, cracks and reddening of the skin were also observed. These symptoms are very similar to the symptoms caused by ring spot, a disease of viral etiology detected in peanuts in the states of São Paulo and Goiás. Therefore, it is important to continue the evaluation of new strains, aiming to develop more productive cultivars adapted to cultivation in Tocantins, as well as elucidating the etiology of the symptoms observed in the experimental area in the 2019/20 harvest.

Keywords: Arachis hypogaea L., Peanut Breeding Program; North region.

\section{Comportamiento agronómico de cultivares e nuevas lineas} de maní en la región central de Tocantins

\section{RESUMEN}

El estado de Tocantins es un importante productor de granos en la región norte de Brasil, que tiene el potencial de producir maní de alta calidad, con el objetivo de satisfacer la creciente demanda de este producto en el mercado interno y externo. Este trabajo tuvo como objetivo evaluar seis líneas de maní tipo Runner alto oleico (1253 OL, 1952 OL, 2055 OL, 2101 OL, 2133 $O L$ y $2136 \mathrm{OL}$ ) en el área experimental de Embrapa, en Palmas-TO. Se utilizaron como controles los cultivares BRS 421 OL y BRS 423 OL. Se utilizó un diseño de bloques al azar con cuatro repeticiones, evaluándose seis líneas en la cosecha 2019/20 y cuatro líneas en la cosecha 2020/21. El manejo de las áreas siguió las recomendaciones para la producción comercial de maní, incluyendo el control químico de malezas y enfermedades foliares. Los datos se sometieron a análisis estadístico utilizando modelos mixtos (REML/BLUP) utilizando el software Selegen. La importancia de los efectos del tratamiento se probó mediante análisis de varianza. No hubo diferencia estadística entre tratamientos (cultivares y cepas) en los dos años de evaluación. Sin embargo, el promedio general del experimento en la cosecha 2019/20

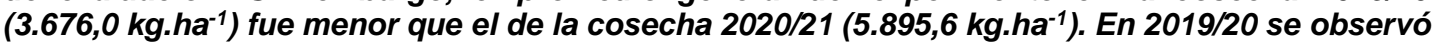
un amarillamiento generalizado de las plantas, aunque no hubo deficiencia de nitrógeno u otro factor asociado al manejo; También se observaron muestras de semillas con deformaciones, manchas, grietas y enrojecimiento de la piel. Estos síntomas son muy similares a los causados por la mancha anular, enfermedad de etiología viral detectada en el maní de los estados de São Paulo y Goiás, por lo que es importante continuar la evaluación de nuevas cepas, con el objetivo de desarrollar cultivares más productivos adaptados. al cultivo en Tocantins, así como dilucidar la etiología de los síntomas observados en el área experimental en la cosecha 2019/20.

Palabras clave: Arachis hypogaea L.; Programa de Mejoramiento de Maní; Región del norte.

\section{Introdução}

A produção de grãos no estado do Tocantins iniciou na década de 1980 (838,7 mil t), com crescimento constante. Na safra atual, é estimada a 
produção de $5.694,5$ mil t de grãos no Tocantins. Os primeiros registros de produção de amendoim neste estado foram feitos a partir da safra 2007/08 (6,3 mil t). Desde então, é observada expressiva variação nas produções anuais desta oleaginosa, com valores mais elevados nas safras 2011/12 (9,2 mil t) e 2014/15 (9,3 mil t). De maneira geral as produtividades de amendoim no único estado da região Norte no bioma Cerrado são altas, superando a média nacional muitas vezes, como em 2016/17 e 2017/18, produzindo $4.800 \mathrm{~kg}^{\mathrm{ha} \mathrm{H}^{-1}}$ (CONAB, 2021).

É interessante observar que a produção de amendoim no Tocantins não segue o mesmo padrão de crescimento observado para soja e milho, apesar das elevadas produtividades registradas. Atualmente, a produção de amendoim é altamente concentrada no estado de São Paulo (mais de $90 \%$ ), onde é comercializada nos mercados internos e externo (mais de $60 \%$ da produção).

Com demanda crescente nos últimos anos, a produção de amendoim tem sido atrativa para produtores de outras regiões do Brasil, em especial no bioma Cerrado. Desde 2010, a Embrapa expandiu o escopo do seu Programa de Melhoramento do Amendoim, incluindo o desenvolvimento de cultivares do tipo Runner alto oleico adaptadas para as principais regiões produtoras de grãos, incluindo o estado do Tocantins, resultando no registro das cultivares BRS 421 OL, BRS 423 OL e BRS 425 OL (SUASSUNA et al., 2019; SUASSUNA et al., 2020). Este trabalho teve o objetivo de avaliar seis linhagens de amendoim do tipo Runner alto oleico (1253 OL, 1952 OL, 2055 OL, 2101 OL, 2133 OL e 2136 OL) na área experimental da Embrapa, em Palmas-TO.

\section{Material e métodos}

Os experimentos foram conduzidos na área experimental da Embrapa, localizada no município de Palmas-TO, nos anos agrícolas 2019/20 e 2020/21. Nas duas safras, as parcelas eram formadas por duas linhas espaçadas $0,8 \mathrm{~m}$ entre si com três metros de comprimento. $\mathrm{O}$ manejo 
do experimento nas duas safras seguiu as recomendações para a cultura, com pleno controle de cercosporioses, plantas invasoras e insetos-praga.

$\mathrm{Na}$ safra 2019/20, o plantio foi realizado no dia 12/12/2019 e a colheita em 15/04/2020 (122 dias após o plantio). A segunda safra realizada em 2020/21, o plantio foi realizado em 11/12/2020 e a colheita em 14/04/2021 (124 dias após o plantio).

O delineamento experimental utilizado foi em blocos casualizados, com quatro repetições. Foram avaliados oito genótipos de amendoim em 2019/20: as cultivares BRS 421 OL, BRS 423 OL e as linhagens 1253 OL, 1952 OL, 2055 OL, 2101 OL, 2133 OL e 2136 OL. Na safra 2020/21 foram avaliadas as cultivares BRS $421 \mathrm{OL}$ e BRS $423 \mathrm{OL}$ e as linhagens $1253 \mathrm{OL}$, 2101 OL, 2133 OL e 2136 OL.

A produtividade de amendoim em casca $\left(\mathrm{kg}^{\mathrm{h}} \mathrm{ha}^{-1}\right)$ foi avaliada mediante a colheita da parcela $\left(5,4 \mathrm{~m}^{2}\right)$. Os dados foram submetidos à análise estatística por meio de modelos mistos (REML/BLUP) utilizando o software Selegen. A significância dos efeitos de tratamentos foi testada por meio da análise de variância (RESENDE, 2016).

\section{Resultados e discussão}

Não houve diferença significativa entre os genótipos avaliados, tanto na safra 2019/20 ou 2020/21 (Tabela 1). No entanto, na safra 2019/20, foram observadas plantas com a parte aérea de coloração mais amarelada e partes de plantas com definhamento, não sendo possível identificar problemas relacionados à nodulação por rizóbio, o que causaria deficiência de nitrogênio, ou outro fator que pudesse causar estes efeitos nas plantas.

A produtividade geral do ensaio de $2019 / 20$ foi baixa $(3.676,00$ $\left.\mathrm{kg} \cdot \mathrm{ha}^{-1}\right)$, mesmo havendo controle químico de cercosporioses. A precipitação também foi normal para o período de cultivo. 
No entanto, ao examinar uma pequena amostra de sementes colhidas na área experimental, foram observados danos variados nas sementes (Figura 1).

Tabela 1. Valores genotípicos preditos (VG) para produtividade de amendoim em casca $\left(\mathrm{kg} \cdot \mathrm{ha}^{-1}\right)$, nas safras 2019/20 e 2020/21. Palmas-TO.

\begin{tabular}{cccc}
\hline \multicolumn{2}{c}{ Safra 2019/20 } & \multicolumn{2}{c}{ Safra 2020/21 } \\
\hline Genótipo & VG $\left({\left.\mathrm{kg} \cdot \mathrm{ha}^{-1}\right)}^{-1}\right.$ & Genótipo & VG $\left(\mathrm{kg} \cdot \mathrm{ha}^{-1}\right)$ \\
\hline BRS 421 OL & $3.775,18$ & BRS 423 OL & $5.916,24$ \\
BRS 423 OL & $3.759,84$ & $1253 \mathrm{OL}$ & $5.902,19$ \\
$2101 \mathrm{OL}$ & $3.716,01$ & BRS 421 OL & $5.894,48$ \\
$2055 \mathrm{OL}$ & $3.675,27$ & $2136 \mathrm{OL}$ & $5.891,53$ \\
1952 OL & $3.667,59$ & $2133 \mathrm{OL}$ & $5.890,88$ \\
2136 OL & $3.648,25$ & $2101 \mathrm{OL}$ & $5.878,20$ \\
2133 OL & $3.601,58$ & - & - \\
\hline 1253 OL & $3.564,28$ & - & - \\
\hline Média geral & $3.676,00$ & & $1,03^{\text {ns }}$ \\
\hline F & $1,23^{\text {ns }}$ & & 15,53 \\
\hline C.V. (\%) & 19,55 & & \\
\hline
\end{tabular}

* - não significativo a 5\% de probabilidade pelo teste F; C.V. - coeficiente de variação.

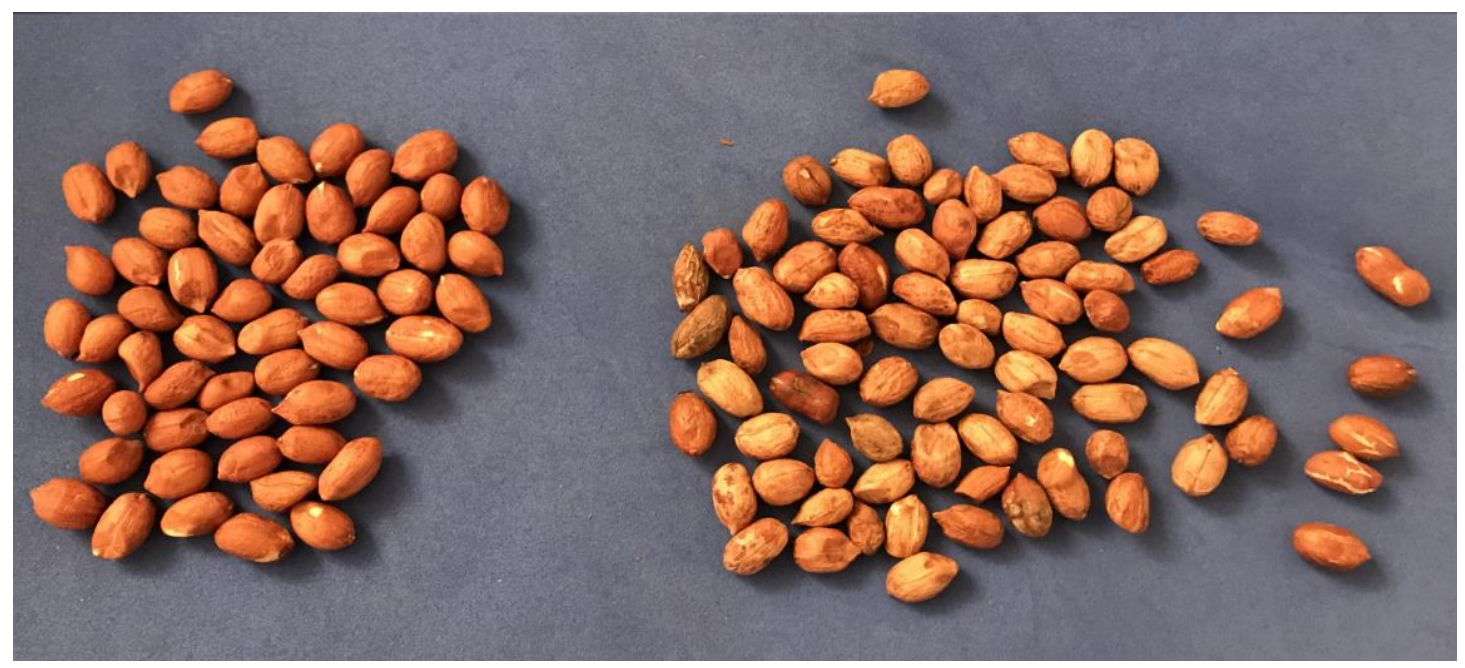

Figura 1. Sementes de amendoim normais (esquerda) e com danos (direita) observadas na área experimental de Palmas-TO, na safra 2019/20. 
Estes danos, caracterizados como deformações das sementes e a presença de manchas, vermelhidão, descoloração, rachaduras na película são associadas à sintomas de mancha anelar, uma doença causada por vírus do gênero Orthotospovirus (SUASSUNA et al., 2020).

$\mathrm{Na}$ safra 2020/21 as plantas da área experimental apresentaram desenvolvimento pleno e a produtividade geral do experimento quase alcançou $6.000,00 \mathrm{~kg}^{-h^{-1}}{ }^{-1}$.

No Brasil, diversas espécies de vírus associados a mancha anelar foram detectadas em São Paulo e Goiás (CAMELO-GARCIA et al., 2014, SUASSUNA et al., 2016) causando sintomas variados na parte aérea. Epidemias de mancha anelar tem ocorrido com certa regularidade na região da Alta Paulista, comprometendo a produção e a qualidade dos grãos (SUASSUNA et al., 2020).

Considerando o potencial da cultura do amendoim na produção de grãos no Cerrado brasileiro, é importante continuar tanto a avaliação de novas linhagens, visando a seleção de cultivares mais produtivas e adaptadas à região, quanto ao correto diagnóstico dos sintomas observados nas plantas e nos grãos na safra 2019/20.

\section{Conclusões}

Não houve diferença entre a produtividade das novas linhagens e a das cultivares BRS 421 OL e BRS 423 OL. É importante realizar novos estudos visando elucidar a etiologia da doença supostamente virótica, observada nas plantas e nos grãos colhidos na safra 2019/20.

\section{Agradecimentos}

Os autores agradecem ao projeto de Melhoramento do Amendoim da Embrapa (SEG 20.18.01.021.00), pelo apoio financeiro. 


\section{Referências}

CONAB. Séries históricas. 2021. Disponível em: <https://www.conab.gov.br/info-agro/safras/serie-historica-das-safras>. Acesso em: 20 jul. 2020.

CAMELO-GARCIA, V. M.; LIMA, E. F. B.; MANSILLA-CÓRDOVA, P. J.; REZENDE, J. A. M.; KITAJIMA, E. W.; BARRETO, M. Occurrence of groundnut ringspot rirus on Brazilian peanut crops. J Gen Plant Pathol, v. 80, p. 282-286, 2014.

RESENDE, M. D. V. Software Selegen-REML/BLUP: a useful tool for plant breeding. Crop Breeding and Applied Biotechnology, v. 16, p. 330-339, 2016.

SUASSUNA, T. M. F. et al. BRS 425: the first runner peanut cultivar related to wild ancestral species. Crop Breeding and Applied Biotechnology, v. 19, n. 3, p. 373-377, 2019.

SUASSUNA, T. M. F.; HEUERT, J.; MARTINS, K. B. B.; BAZANELLA, M. R.; XAVIER, M. F. N.; RIBEIRO, R. P. Avaliação de manchas nos grãos de amendoim produzidos sob epidemia severa de mancha anelar. South American Sciences, v. 1, n. 1, p. e2014, 2020a.

SUASSUNA, T. M. F. et al. 'BRS 421' and 'BRS 423': high oleic peanut cultivars for production in Brazil. Crop Breeding and Applied Biotechnology, v. 20, p. e28932018, 2020b.

SUASSUNA, T. M. F.; ALMEIDA, M. M. S.; RESENDE, R. O.; LIMA, M. G. A.; FARIA, J. C.; HEUERT, J.; SUASSUNA, N. D. Identificação de Tospovirus em amostras de amendoim com sintomas de clareamento nas nervuras no estado de Goiás. In: Anais do Encontro Sobre a Cultura do Amendoim, 13., 2016, Jaboticabal. Anais eletrônicos... Campinas: GALOÁ, 2016. 